Article

\title{
Increasing Susceptibility of Drug-Resistant Candida albicans to Fluconazole and Terbinafine by 2(5H)-Furanone Derivative
}

\author{
Irshad S. Sharafutdinov ${ }^{1, *,+}\left(\mathbb{D}\right.$, Georgii D. Ozhegov ${ }^{1,2,+}$, Alina E. Sabirova ${ }^{1,+}$, \\ Valentina V. Novikova ${ }^{3}$, Svetlana A. Lisovskaya ${ }^{4,5}$, Alsu M. Khabibrakhmanova ${ }^{6}$, \\ Almira R. Kurbangalieva ${ }^{6}$, Mikhail I. Bogachev ${ }^{7}$ (D) and Airat R. Kayumov ${ }^{1, * \mathbb{D}}$ \\ 1 Laboratory of Molecular Genetics of Microorganisms, Institute of Fundamental Medicine and Biology, Kazan \\ Federal University, Kazan 420008, Russia; georgii_provisor@mail.ru (G.D.O.); alinka.zam@mail.ru (A.E.S.) \\ 2 Industrial Drug Technology and Biotechnology, Perm State Pharmaceutical Academy, Perm 614990, Russia \\ 3 Department of Microbiology, Perm State Pharmaceutical Academy, Perm 614990, Russia; \\ vvnperm@yandex.ru \\ 4 Kazan Scientific Research Institute of Epidemiology and Microbiology, Kazan 420015, Russia; \\ s_lisovskaya@mail.ru \\ 5 Kazan State Medical University, Kazan 420012, Russia \\ 6 Biofunctional Chemistry Laboratory, Alexander Butlerov Institute of Chemistry, Kazan Federal University, \\ Kazan 420008, Russia; alsu-khabibrakhmanova@mail.ru (A.M.K.); almira99@mail.ru (A.R.K.) \\ 7 Radio Systems Department \& Biomedical Engineering Research Centre, St. Petersburg Electrotechnical \\ University, St. Petersburg 197376, Russia; rogex@yandex.com \\ * Correspondence: irsultanovich@gmail.com (I.S.S.); kairatr@yandex.ru (A.R.K.); \\ Tel.: +7-927-402-1105 (I.S.S.); +7-904-665-1908 (A.R.K.) \\ + Authors contributed equally to this manuscript.
}

Received: 6 January 2020; Accepted: 1 February 2020; Published: 2 February 2020

\begin{abstract}
The frequency of mycoses caused by drug-resistant fungal pathogen Candida albicans has increased drastically over the last two decades. The spread of drug-resistant strains, along with the limitations of currently available antifungals, complicates the management of fungal infections, thereby representing great challenges for clinical healthcare. Among various antimicrobial pharmacophores, $2(5 \mathrm{H})$-furanone derivatives have demonstrated antimicrobial, antifungal, and antibiofilm activities. In this study, we report the antifungal activity of the $2(5 H)$-furanone derivative $\mathbf{F 1 0 5}$, consisting of three pharmacophores, namely chlorinated $2(5 \mathrm{H})$-furanone, sulfonyl group, and l-menthol moiety. Although exhibiting moderate antifungal activity alone with the minimum inhibitory concentration (MIC) values of 32-256 $\mu \mathrm{g} / \mathrm{mL}, \mathbf{F 1 0 5}$ potentiates the activity of fluconazole and terbinafine with fractional inhibitory concentration index (FICI) values of $0.27-0.50$. Thus, $16 \mu \mathrm{g} / \mathrm{mL}$ of F105 reduced the MICs of these antifungals against fluconazole-resistant $C$. albicans isolates four-fold, achieving similar values as for the intermediately susceptible phenotype. Confocal laser scanning microscopy revealed that the fluorescent 2(5H)-furanone derivative F145 was also able to penetrate through biofilms formed by C. albicans. Indeed, in the presence of F105, even sub-MIC concentrations of both fluconazole and terbinafine led to significant reduction of $C$. albicans CFUs in the mature biofilm. Thus, F105 appears to be a promising candidate for the development of novel antifungal agents as well as enhancers of current antifungal agents, particularly for the treatment of drug-resistant C. albicans infections.
\end{abstract}

Keywords: 2(5H)-furanones; biofilm; Candida albicans; drug resistance; synergy 


\section{Introduction}

Candida albicans, commonly found in human microbiota, can under certain conditions cause a range of opportunistic diseases, especially in immunocompromised patients [1]. Thus, the overgrowth of C. albicans often leads to chronic infections of mouth [2], skin [3], or genitourinary tract [4] known as candidiasis.

Various treatment options for C. albicans infections are available to date, ranging from topical antifungal agents chlorohexidine and nystatin [5] to systemic drugs such as terbinafine, fluconazole, and novel echinocandins [6]. However, rising resistance of Candida to antifungals requires the development of new drugs $[7,8]$. Thus, even though no clinical breakpoints for terbinafine have been defined so far, terbinafine-resistant $C$. albicans clinical isolates have been widely reported $[9,10]$. Additionally, a triazole antifungal agent fluconazole, commonly prescribed for Candida infections, is unfortunately predisposed to causing the development acquired resistance since it exhibits only fungistatic activity [11].

Besides genetically determined resistance, $C$. albicans forms rigid biofilms where cells become phenotypically resistant to antimycotics and to the immune system of the host [12]. The extracellular polymeric substances of the biofilm matrix provide a diffusional barrier for the drug, thereby leading to low susceptibility of cells to antimycotics [13].

Amongst novel approaches targeting biofilm-associated infections, the $2(5 H)$-furanone derivatives have been suggested as inhibitors of the bacterial biofilm formation [14,15]. In particular, furanones have been shown to quench the bacterial quorum-sensing pathways in, for example, Pseudomonas aeruginosa, Escherichia coli, and Staphylococcus $[14,16]$. Some 2(5H)-furanone derivatives have also been reported to exhibit pronounced biocidal activity against biofilm-embedded Staphylococcus aureus [17], S. epidermidis [18], and Bacillus cereus [19]. Nevertheless, the effect of 2(5H)-furanone derivatives on fungal cells is less well understood to date. Halogenated 3-phenyl-5-acyloxymethyl derivatives of $2(5 H)$-furanone demonstrated antifungal activity against $C$. albicans with minimum inhibitory concentration (MIC) values ranging from 0.5 to $2 \mu \mathrm{g} / \mathrm{mL}$ [20]. However, fluconazole-resistant C. albicans demonstrated lower sensitivity characterized by MIC $=8 \mu \mathrm{g} / \mathrm{mL}$. In another study, 3-arylidene-5-(4-chloro/ethyl-phenyl)-furanones exhibited both antibacterial and antifungal activity with MIC values of $12.5-50 \mu \mathrm{g} / \mathrm{mL}$ against both C. albicans and S. aureus ATCC-29737 [21]. The obvious disadvantage of furanones is their high toxicity against eukaryotic cells. In particular, the cytotoxicity concentration $\left(\mathrm{CC}_{50}\right)$ values of active compounds are in the range of $1.5-32 \mu \mathrm{g} / \mathrm{mL}$, thus exceeding the corresponding MICs only 2-8-fold $[15,17,19,22-24]$ and thereby limiting their direct application to topical use only.

The aim of this work was to evaluate the antifungal activity of F105 against a set of C. albicans isolates. We have investigated the antifungal activity of 3-chloro-5(S)-[(1R,2S,5R)-2-isopropyl5-methylcyclohexyloxy]-4-[4-methylphenylsulfonyl]-2(5H)-furanone (F105) along with its analogues 3-chloro-5-hydroxy-4-[(4-methylphenylsulfonyl)]-2(5H)-furanone (F70) [25], 3-chloro-5(S)-[(1R,2S,5R)-2-isopropyl-5-methylcyclohexyloxy]-4-[4-methylphenylsulfanyl]-

$2(5 H)$-furanone (F104) [17], and the fluorescent 2(5H)-furanone derivative 5-[2-(benzothiazol-2-yl)-4-bromophenoxy]-3-chloro-4-[(4-methylphenyl)sulfonyl]-2(5H)-furanone (F145) [26] (see Figure 1 for structures). We found that F105 was able to potentiate the antifungal activity of fluconazole and terbinafine against $C$. albicans cells, including resistant isolates. 
<smiles>Cc1ccc(S(=O)(=O)C2=C(Cl)C(=O)OC2O)cc1</smiles>

F70<smiles>Cc1ccc(SC2=C(Cl)C(=O)OC2OC2CC(C)CCC2C(C)C)cc1</smiles><smiles>Cc1ccc(S(=O)(=O)C2=C(Cl)C(=O)OC2OC2CC(C)CCC2C(C)C)cc1</smiles>

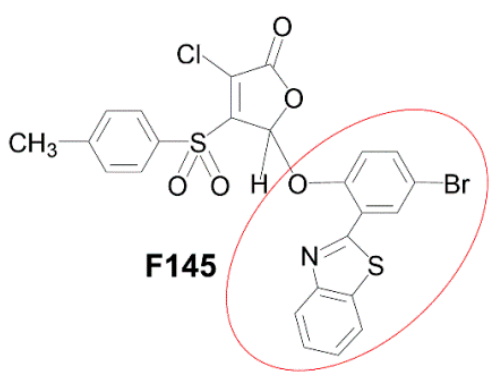

Figure 1. Molecular structures of 2(5H)-furanone derivatives F70 [25], F104 [17], F105 [17], and F145 [26]. The red circle in the structure of F145 indicates a fluorescent 2-(benzothiazol-2-yl)-4-bromophenol (BTBP) moiety.

\section{Results}

\subsection{Antimycotic Activity of 2(5H)-Furanone Derivatives}

\subsubsection{Susceptibility of C. albicans Isolates to F105 and Conventional Antimycotics}

The antimycotic activity of 2(5H)-furanone derivative F105 carrying sulfonyl and l-menthol moieties was evaluated using a range of $C$. albicans clinical isolates $(n=26)$ and C. albicans NCTC ${ }^{\circledR} 885-653$ from the National Collection of Type Cultures (Perm, Russia) (Table 1). All clinical isolates were resistant to fluconazole (MIC $\geq 8 \mu \mathrm{g} / \mathrm{mL}$ according to M27-S4 guidelines prepared by the Clinical Laboratory Standards Institute (CLSI)), and moderately susceptible to terbinafine and nystatine $[9,27]$. F105 completely inhibited the growth of various C. albicans isolates at concentrations of 32-256 $\mu \mathrm{g} / \mathrm{mL}$ and higher, suggesting a weak antifungal activity. No antifungal activity was detected for other compounds F70 and F104, lacking, respectively, sulfonyl or l-menthol moieties in comparison with F105 (see Figure 1 for the structures). The compound F145, which in comparison to F105 had a substitution of $l$-menthol moiety by fluorescent 2-(benzothiazol-2-yl)-4-bromophenol (BTBP), also demonstrated no antifungal activity. These data confirm that both sulfonyl and $l$-menthol moieties are strictly required for the antimycotic activity.

2.1.2. F105 Potentiated the Antifungal Activity of Fluconazole and Terbinafine against C. albicans Cells

2(5H)-Furanone derivatives have been previously reported to increase the antimicrobial activity of antibiotics $[17,19,24,28]$. In particular, F105 exhibits pronounced synergy with aminoglycosides (kanamycin, gentamycin, and amikacin) and benzalkonium chloride, significantly reducing the MICs of these compounds for S. aureus [17]. Therefore, we tested whether F105 is capable of potentiating antifungal activities as well. C. albicans K6631-19, with a moderate susceptibility to all antimycotics, was chosen for this test (Table 1). While the molecular structure of nystatin contains a deoxysugar D-mycosamine, an aminoglycoside [29], the FICI $_{\text {min }}$ value was 0.63 when combined F105 with nystatin, suggesting no interaction (Table 2). In marked contrast, a pronounced synergy was observed for F105 in combination with fluconazole and terbinafine, as their antifungal activity was considerably increased in the presence of F105. The checkerboard assay revealed $\mathrm{FICI}_{\mathrm{min}}=0.28$ for both these antifungals in combination with F105. The calculated effective concentration $\left(\mathrm{EC}_{50}\right)$ values of F105 (determined as 
the concentration leading to the 2-fold reduction in MIC of either fluconazole or terbinafine) were 9.47 and $4.54 \mu \mathrm{g} / \mathrm{mL}$, respectively (Figure 2, Table 2).

Table 1. Susceptibility of Candida albicans clinical isolates to F105 and conventional antimycotics.

\begin{tabular}{cccccc}
\hline \multirow{2}{*}{ Isolate/Strain } & Source & \multicolumn{3}{c}{ MIC $(\boldsymbol{\mu g} / \mathbf{m L})$} \\
\cline { 2 - 5 } & & F105 & Fluconazole & Terbinafine & Nystatin \\
\hline NCTC ${ }^{\circledR} 885-653$ & NCTC Collection & 64 & 64 & 8 & 8 \\
K3836-19 & Phlegm & 64 & 32 & 4 & 4 \\
K4026-19 & Buccal swab & 32 & 8 & 2 & 8 \\
K4085-19 & Buccal swab & 256 & 16 & 4 & 4 \\
K4146-19 & Buccal swab & 256 & 16 & 4 & 8 \\
K46-19 & Buccal swab & $>256$ & 128 & 8 & 8 \\
K47-19 & Buccal swab & 256 & 64 & 32 & 16 \\
K4940-19 & Buccal swab & 64 & 128 & 16 & 8 \\
K4941-19 & Buccal swab & $>256$ & 64 & 8 & 8 \\
K4956-19 & Buccal swab & $>256$ & $>128$ & 16 & 4 \\
K4978-19 & Buccal swab & 64 & 32 & 8 & 2 \\
K5002-19 & Cervical canal & $>256$ & 128 & 16 & 8 \\
K5007-19 & Buccal swab & 64 & $>128$ & 16 & 4 \\
K5012-19 & Buccal swab & 64 & 64 & 32 & 8 \\
K5014-19 & Buccal swab & 64 & 16 & 16 & 8 \\
K5030-19 & Buccal swab & 32 & 128 & 16 & 8 \\
K5038-19 & Urethral mucosa & $>256$ & 32 & 8 & 16 \\
K5050-19 & Buccal swab & 256 & 64 & 8 & 2 \\
K5061-19 & Buccal swab & 128 & 32 & 16 & 4 \\
K5077-19 & Buccal swab & 128 & 64 & 16 & 4 \\
K5081-19 & Buccal swab & 128 & 64 & 32 & 4 \\
K5092-19 & Buccal swab & 256 & 128 & 16 & 8 \\
K5094-19 & Buccal swab & $>256$ & 64 & 16 & 8 \\
K5096-19 & Buccal swab & 32 & 64 & 16 & 2 \\
K5097-19 & Buccal swab & 256 & 64 & 16 & 4 \\
K625-19 & Vaginal swab & 256 & 32 & 4 & 4 \\
K6631-19 & Throat swab & $>256$ & 32 & 4 & 2 \\
\hline
\end{tabular}

${ }^{*}$ The above data are medians calculated from a series of six independent measurements.

Table 2. Minimum inhibitory concentration (MIC), fractional inhibitory concentration (FIC), FICI, and $\left(\mathrm{EC}_{50}\right)$ values of 2(5H)-furanone derivatives on C. albicans K6631-19.

\begin{tabular}{ccccccc}
\hline & MIC & MIC (F105) & FIC & FIC (F105) & FICI $_{\text {min }}$ & EC $_{\mathbf{5 0}}$ \\
\hline Fluconazole & 32 & 512 & 8 & 16 & 0.28 & 9.47 \\
Nystatin & 4 & 512 & 2 & 64 & 0.63 & 106.2 \\
Terbinafine & 4 & 512 & 1 & 16 & 0.28 & 4.54 \\
\hline
\end{tabular}

To confirm the synergistic effect of F105 along with fluconazole and terbinafine, additional experiments were performed using C. albicans NCTC ${ }^{\circledR} 885-653$ and four C. albicans clinical isolates with various susceptibilities to antimycotics. The FICI values for F105 and fluconazole revealed by the checkerboard assay ranged from 0.27 to 0.38 , with corresponding $\mathrm{EC}_{50}$ values in the range of 4.72-27.89 $\mu \mathrm{g} / \mathrm{mL}$ (Table 3). F105 in combination with terbinafine exhibited FICI values in the range of 0.28-0.5 for five tested strains, suggesting a rather synergistic effect, while one strain showed FICI $=0.56$. $\mathrm{EC}_{50}$ values remained within the range of $1.57-26.6 \mu \mathrm{g} / \mathrm{mL}$. The obtained data suggest that F105 in most cases potentiated the antimycotic activity of fluconazole and terbinafine against even resistant C. albicans cells (with the exception of C. albicans K5061-19 when F105 was combined with terbinafine). Based on these data, a potential four-fold enhancement of the effect of both fluconazole and terbinafine in the presence of $16 \mu \mathrm{g} / \mathrm{mL}$ of F105 could be expected. Thus, taking into account 
the rapid development of fluconazole-resistant strains among C. albicans isolates [30], F105 could be a perspective candidate to reduce the MICs of conventionally used antifungals and maintain their efficacy for the treatment of drug-resistant fungi [8].
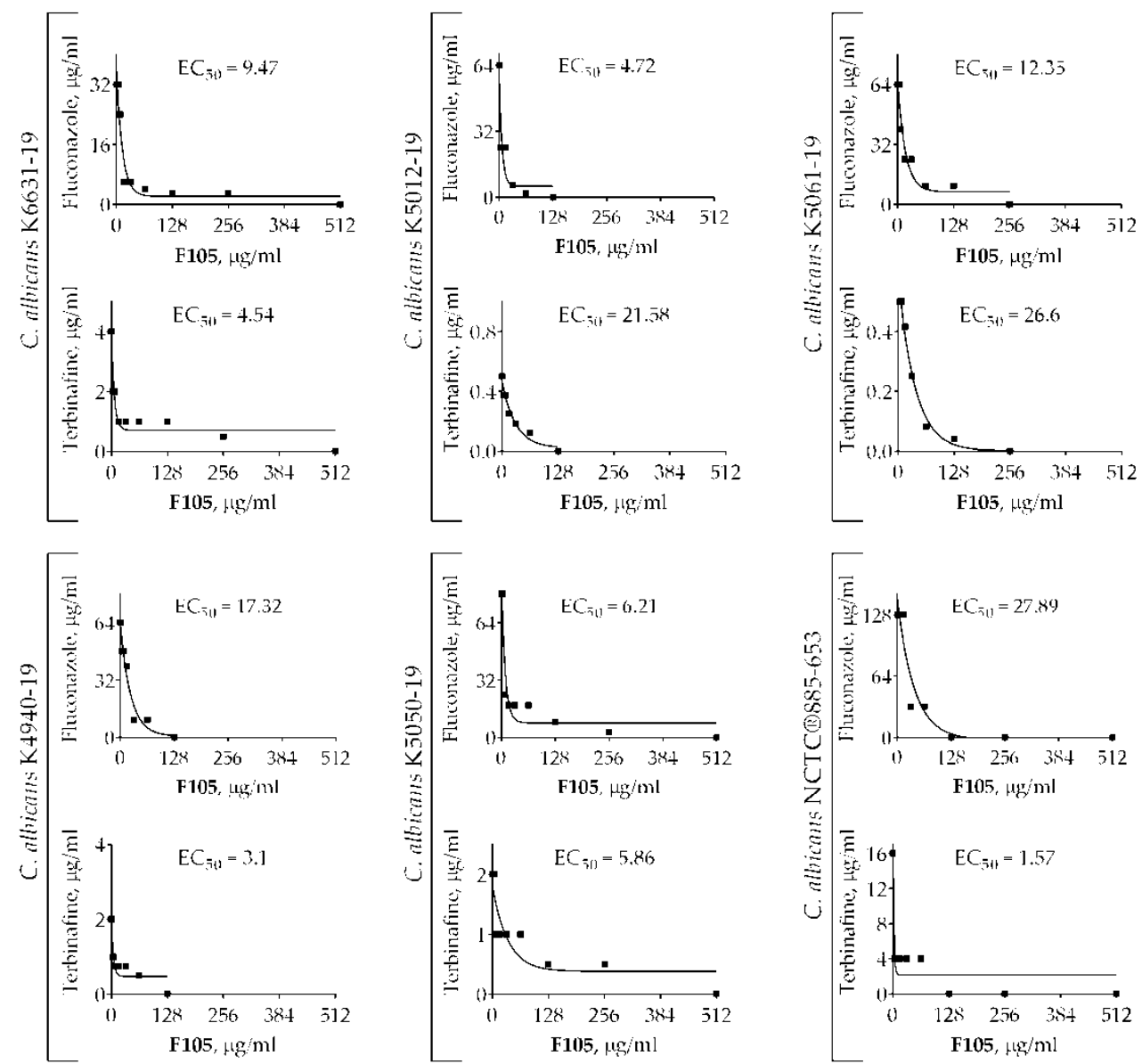

Figure 2. The $\mathrm{EC}_{50}$ values of F105 leading to the 2-fold MIC reduction of fluconazole and terbinafine on different strains of $C$. albicans.

Table 3. Synergistic effect of F105 with fluconazole and terbinafine on C. albicans strains. MIC and FIC are expressed in $\mu \mathrm{g} / \mathrm{mL}$.

\begin{tabular}{|c|c|c|c|c|c|c|c|}
\hline & C. albicans strain & $\begin{array}{c}\text { MIC } \\
\text { (F105) }\end{array}$ & $\begin{array}{l}\text { MIC } \\
\text { (FLC) }\end{array}$ & FIC (F105) & FIC (FLC) & $\mathrm{FICI}_{\min }$ & $\begin{array}{c}\mathrm{EC}_{50} \\
\text { (F105) }\end{array}$ \\
\hline \multirow{7}{*}{$\begin{array}{l}\text { F105 + Fluconazole } \\
\text { (FLC) }\end{array}$} & K6631-19 & 512 & 32 & 16 & 8 & 0.28 & 9.47 \\
\hline & K5012-19 & 64 & 64 & 16 & 4 & 0.31 & 4.72 \\
\hline & K5061-19 & 128 & 32 & 4 & 8 & 0.31 & 12.35 \\
\hline & K4940-19 & 64 & 128 & 16 & 16 & 0.38 & 17.32 \\
\hline & K5050-19 & 256 & 64 & 4 & 16 & 0.27 & 6.21 \\
\hline & NCTC ${ }^{\circledR} 885-653$ & 64 & 64 & 16 & 16 & 0.5 & 27.89 \\
\hline & C. albicans strain & $\begin{array}{l}\text { MIC } \\
\text { (F105) }\end{array}$ & $\begin{array}{l}\text { MIC } \\
\text { (TRB) }\end{array}$ & FIC (F105) & FIC (TRB) & $\mathrm{FICI}_{\min }$ & $\begin{array}{c}\mathrm{EC}_{50} \\
\text { (F105) }\end{array}$ \\
\hline \multirow{6}{*}{$\begin{array}{c}\text { F105 + Terbinafine } \\
\text { (TRB) }\end{array}$} & K6631-19 & 512 & 4 & 16 & 1 & 0.28 & 4.54 \\
\hline & K5012-19 & 64 & 32 & 16 & 8 & 0.5 & 21.58 \\
\hline & K5061-19 & 128 & 16 & 8 & 2 & 0.56 & 26.6 \\
\hline & K4940-19 & 64 & 16 & 4 & 4 & 0.31 & 3.1 \\
\hline & K5050-19 & 256 & 8 & 64 & 2 & 0.5 & 5.86 \\
\hline & NCTC ${ }^{\circledR} 885-653$ & 64 & 8 & 2 & 2 & 0.28 & 1.57 \\
\hline
\end{tabular}


2.2. F105 Enhanced the Capacity of Fluconazole and Terbinafine to Disturb C. albicans Plasma Membrane Integrity

The cell wall of C. albicans consists of an external protein coat and an internal skeletal layer [31,32], which protects the plasma membrane from damage and acts as a diffusional barrier for many antifungals [33,34]. The mechanism of antifungal activity of both fluconazole and terbinafine is based on disordering of the ergosterol synthesis pathway, an essential component of the C. albicans cytoplasmic membrane. Consequent changes in the plasma membrane permeability lead to fungal cell death. F105 has been shown previously to directly interact with peptide molecules in this way, leading to the drop of the membrane potential of bacterial cells [17]. Therefore, we next analyzed the ability of F105 to influence the membrane potential in C. albicans either alone or in combination with fluconazole and terbinafine.

Four C. albicans clinical isolates $(4940,5012,5050,5061)$ exhibiting different susceptibilities to antifungals (see Table 1 for details) were treated with $16 \mu \mathrm{g} / \mathrm{mL}$ of F105 and fluconazole $(1 \times, 2 \times$, or $4 \times$ of corresponding MIC) either alone or in combination. Treatment of C. albicans cells with $16 \mu \mathrm{g} / \mathrm{mL}$ of F105 did not lead to a significant decrease in the membrane potential of any of the studied isolates (Figure 3). In marked contrast, the combination of F105 with fluconazole led to a drastic decrease of the membrane potential in C. albicans 4940 and C. albicans 5061, while the effect was less pronounced in C. albicans 5012 and C. albicans 5050 (Figure 3a). These discrepancies in the susceptibility of different strains to F105 and antifungals could be attributed to their particular resistance mechanisms by either efflux pump activation in C. albicans 4940 and C. albicans 5061, or ergosterol biosynthesis modification in C. albicans 5012 and C. albicans 5050. Remarkably, the combination of F105 with terbinafine caused a sharp drop in the membrane potential in all four strains (Figure 3b). The observed effects confirmed the revealed synergy of fluconazole and terbinafine with F105. These data together with the observation of a 16-fold drop in F105 FIC in the checkerboard assay allowed the speculation that C. albicans cells exhibit low permeability for F105 itself. On the other hand, the membrane disorder caused by either fluconazole or terbinafine seemed to facilitate the penetration of F105 into the cell. To test that assumption, the membrane potential was measured at sub-MIC concentrations of antifungals and various concentrations of F105 (Figure 4). With the increase of F105 concentration, the relative membrane potential decreased. In the presence of sub-MIC of fluconazole and furanone, a significantly steeper drop in membrane potential could be observed in C. albicans 4940, C. albicans 5012, and C. albicans 5061, although at high concentrations of F105 only. In contrast, sub-MIC concentrations of terbinafine led to a faster loss of 3,3'-diethyloxacarbocyanine iodide $\left(\mathrm{DioC}_{2}(3)\right)$ fluorescence only in $C$. albicans 5012 and C. albicans 5050 strains. The above also confirmed the furanone derivative's cytotoxic effect, similarly to observations made in earlier studies $[17,19,23,26]$. The variations in observed speed of membrane potential drop could be attributed to the fact that measurements reflected the changes only $1 \mathrm{~h}$ after starting the treatment. 


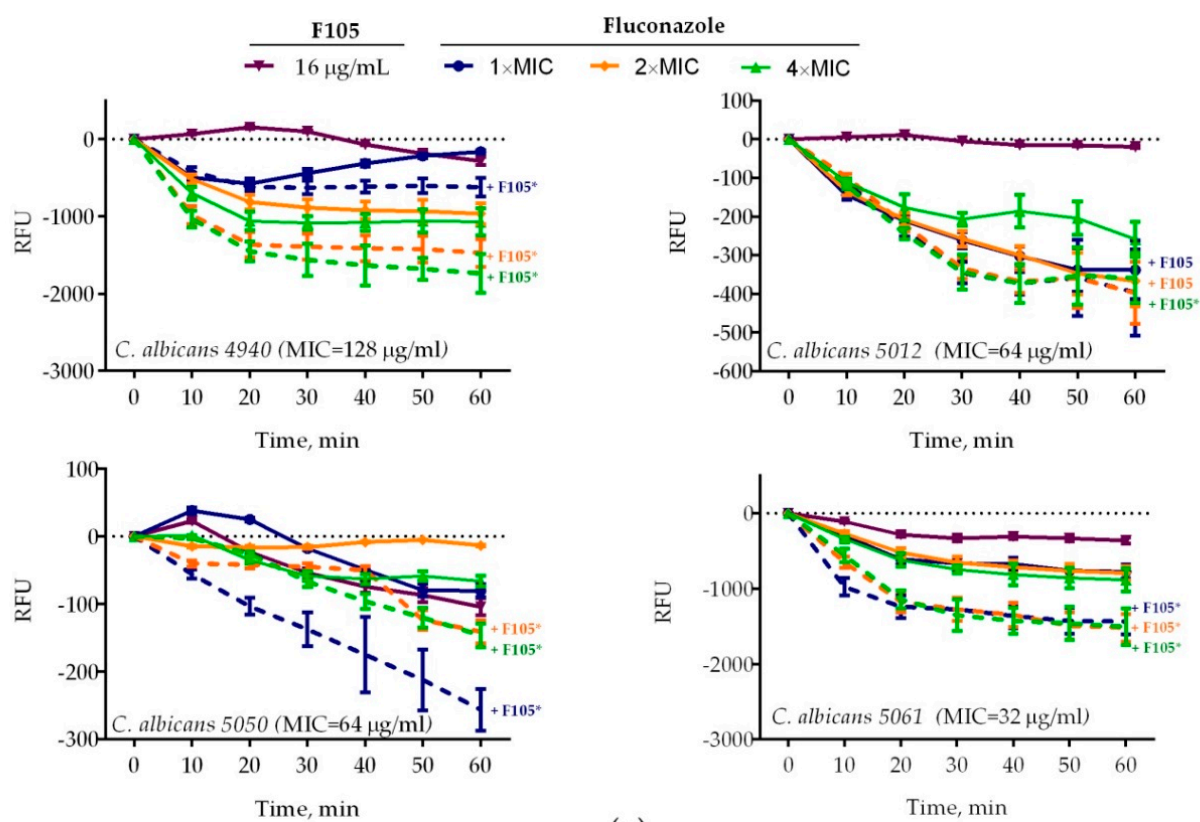

(a)

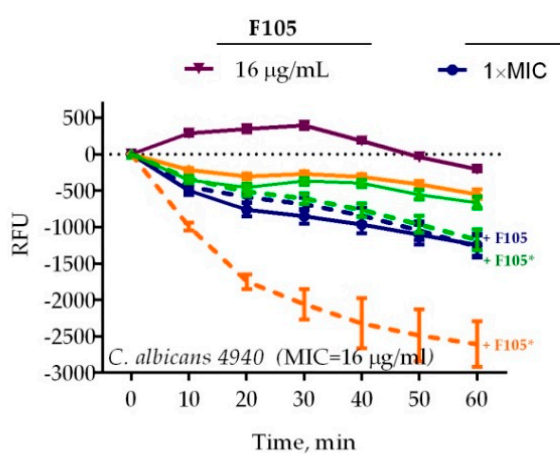

Terbinafine
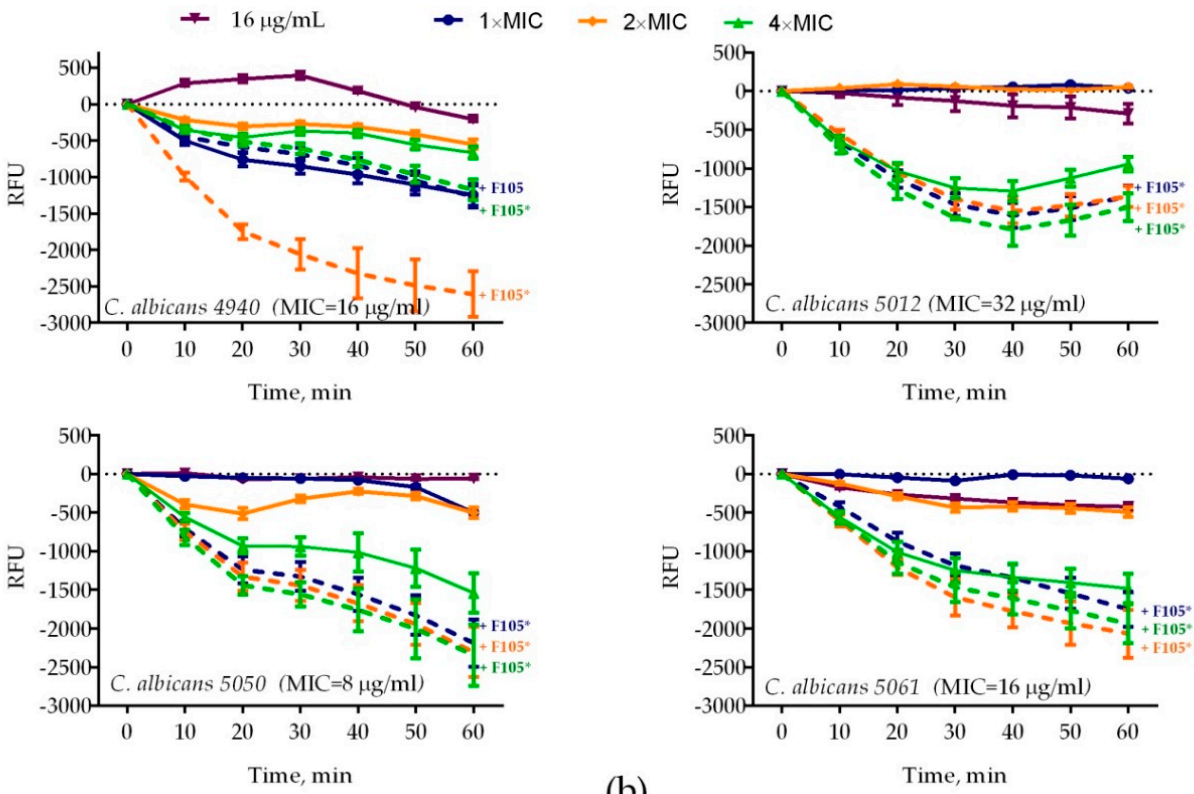

(b)

Figure 3. Relative membrane potentials of C. albicans isolates after treatment with F105 $16 \mu \mathrm{g} / \mathrm{mL}$ and/or (a) fluconazole or $(\mathbf{b})$ terbinafine $(1 \times, 2 \times$, or $4 \times$ of corresponding MIC, see Table 1 for values) either alone or in combination. C. albicans cells in the late exponential growth phase were harvested, washed with phosphate-buffered saline (PBS), and resuspended in PBS supplemented with $10 \mu \mathrm{M} \mathrm{DioC}_{2}(3)$. After 30 min preincubation, compounds were added as indicated and the fluorescence was measured for $60 \mathrm{~min}$ with $10 \mathrm{~min}$ intervals. Lines represent the median values with IQRs from five independent measurements. In cases marked with *, the measured RFUs after $60 \mathrm{~min}$ of exposure were significantly lower in the presence of F105 compared to similar treatments in the absence of F105 according to the Kruskal-Wallis statistical test at $p<0.05$. Corresponding MICs of antifungals are given in parentheses after the strain names. 

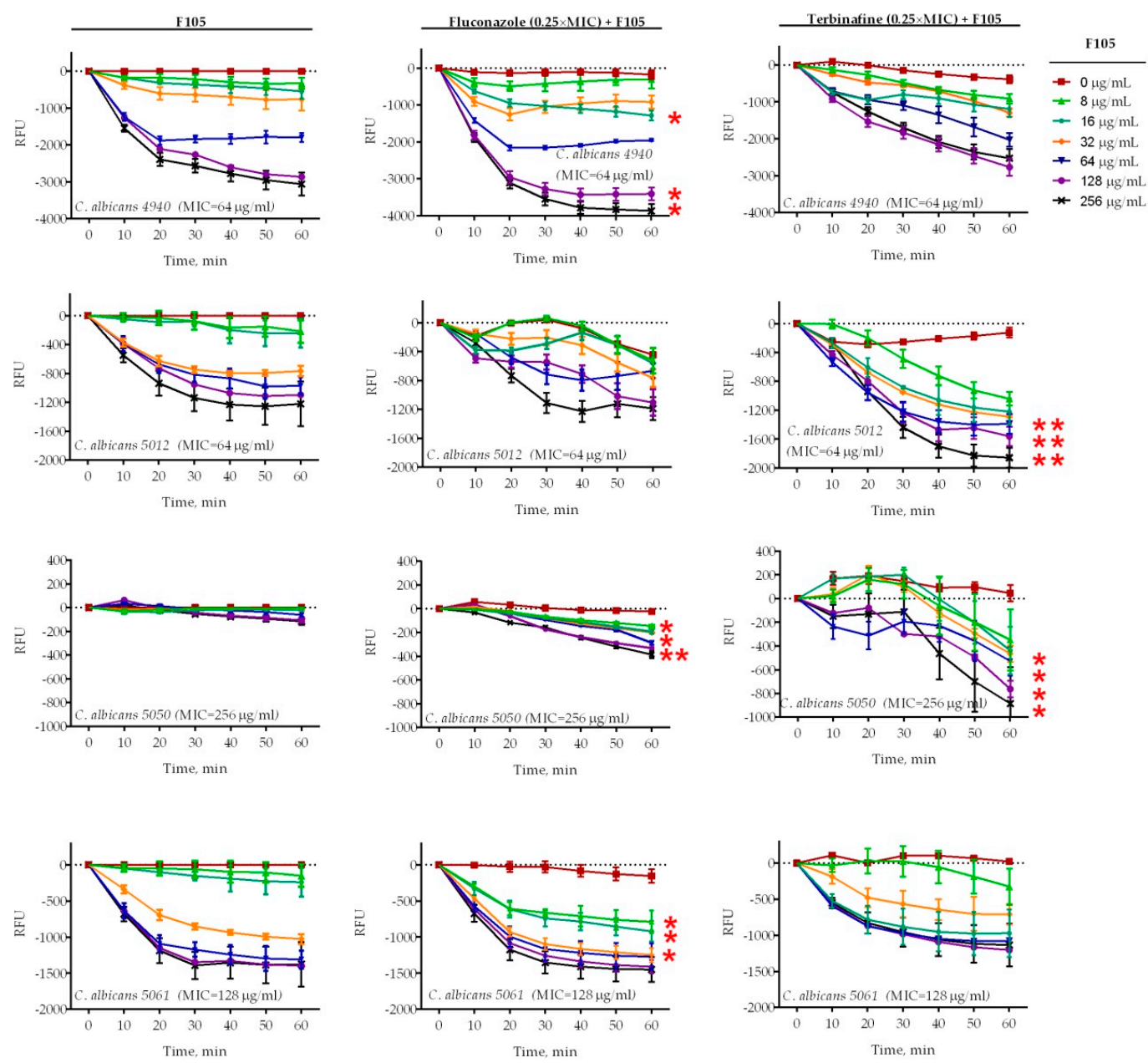

Figure 4. Relative membrane potentials of $C$. albicans isolates after treatment with various concentrations of F105 and 0.25× MIC of fluconazole or terbinafine (see Table 1 for MIC values). C. albicans cells in the late exponential growth phase were harvested, washed with PBS, and resuspended in PBS supplemented with $10 \mu \mathrm{M} \mathrm{DioC}_{2}(3)$. After $30 \mathrm{~min}$ preincubation, compounds were added as indicated and the fluorescence was measured for $60 \mathrm{~min}$ with $10 \mathrm{~min}$ intervals. Lines represent the median values with IQRs from five independent measurements. In cases marked with *, the measured relative fluorescence units (RFUs) after $60 \mathrm{~min}$ of exposure were significantly lower in the presence of F105 compared to similar treatments in the absence of F105 according to the Kruskal-Wallis statistical test at $p<0.05$. Corresponding MICs for F105 are given in parentheses after the strain names.

\subsection{Penetration of Fluorescent 2(5H)-Furanone Derivative into C. albicans Cells}

The reduction of the F105 FIC in the presence of either fluconazole or terbinafine allowed the suggestion that F105 diffusion into the cell is complicated and is efficient only after membrane disturbance. To visualize the furanone penetration into $\mathrm{C}$. albicans cells, the $2(5 \mathrm{H})$-furanone derivative F145, the fluorescent analogue of F105, was used. C. albicans cells were stained with both F145 and 3,3'-dihexyloxacarbocyanine iodide $\left(\operatorname{DioC}_{6}(3)\right)$ and analyzed using confocal laser scanning microscopy (CLSM). Since $\mathrm{DioC}_{6}(3)$ is a membrane-potential-sensitive dye, the accumulation of $\operatorname{DioC}_{6}(3)$ could be observed mainly in mitochondria and partially in the cytoplasmic membrane (Figure 5, yellow arrows). F145 fluorescence was predominantly observed in the fungal cell wall after 30 min incubation (Figure 5). After $6 \mathrm{~h}$ incubation, strong F145 fluorescence was mainly observed within the cell nucleus, suggesting its slow penetration through the cell wall. Interestingly, the blue fluorescence of BTBP, the fluorescent moiety of F145, was observed in mitochondria in overlay with $\mathrm{DioC}_{6}(3)$ as well as in the 
nucleus after only 30 min of incubation. These data clearly indicate that F145 binds initially with the cell wall of $C$. albicans and then slowly penetrates into the fungal cell and accumulates in its nucleus.
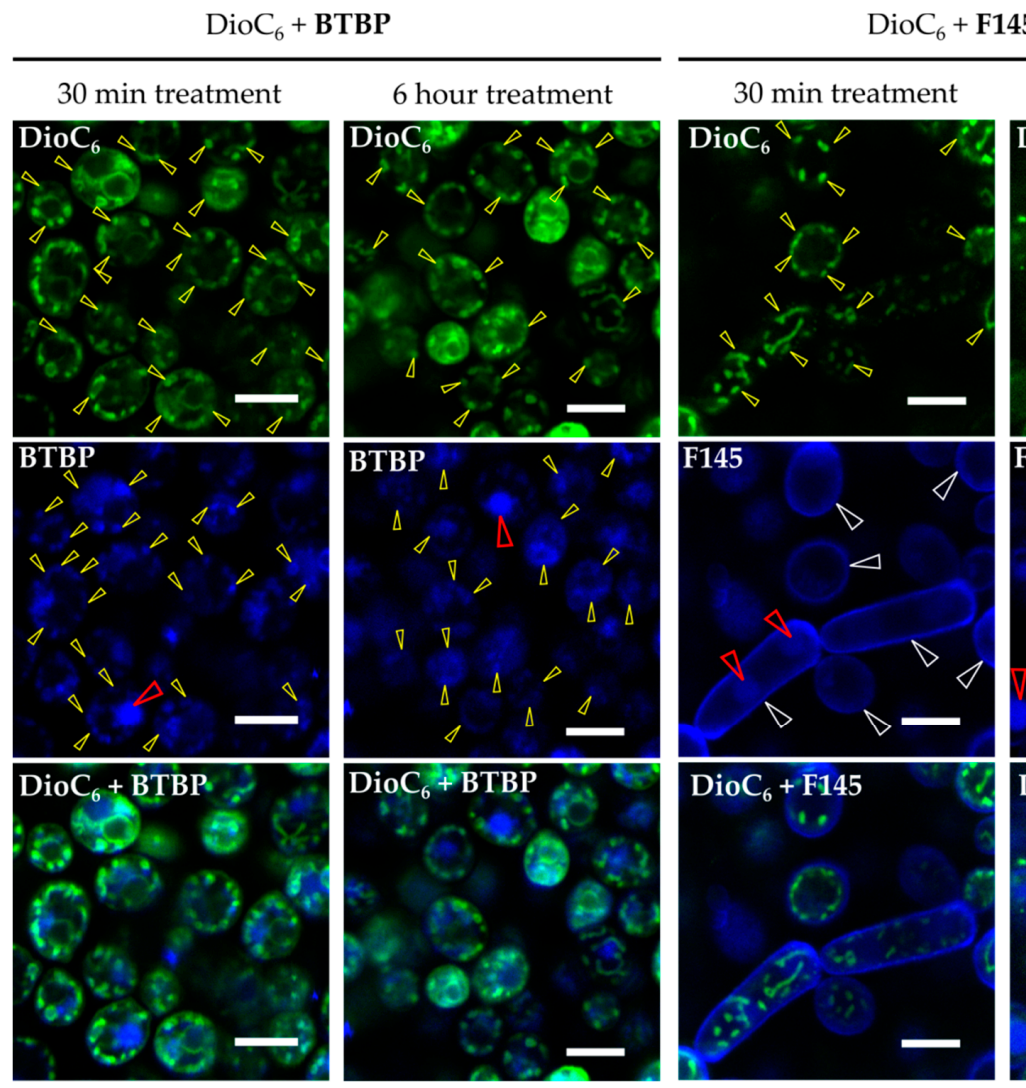

6 hour treatment
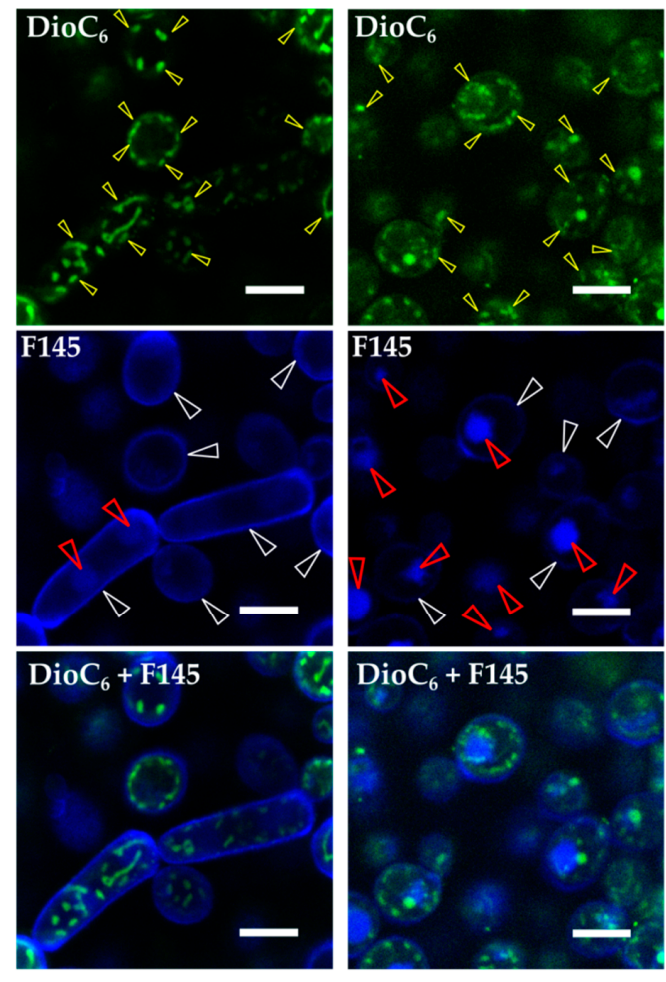

Figure 5. CLSM of C. albicans cells treated with $\mathrm{DioC}_{6}(3)$ and F145 for either 30 min or 6 h; control treated with $\mathrm{DioC}_{2}(3)$ and BTBP fluorophore for $30 \mathrm{~min}$ or $6 \mathrm{~h}$, respectively. White arrows indicate the stained cell wall, yellow arrows show the stained mitochondria, and red arrows indicate the stained nucleus. Scale bar is $5 \mu \mathrm{m}$.

To test the assumption that membrane disturbance facilitates the furanone derivative's diffusion into the cell, $C$. albicans was treated for $4 \mathrm{~h}$ with either fluconazole or terbinafine $(1 \times$ or $2 \times \mathrm{MIC})$ and then F145 was added. After 30 min of incubation, the cells were analyzed with CLSM. In the presence of F145 either alone or in combination with $1 \times$ MIC of the antimycotics, fluorescence was observed only in the cell wall (Figure 6). In contrast, in cells pre-treated with $2 \times$ MIC of either fluconazole or terbinafine followed by the F145 addition, pronounced intracellular fluorescence could be observed, confirming that membrane disorder is required for the furanone derivative to penetrate into the cell.

Since the F145 fluorescence was observed in the nucleus, we further analyzed whether furanone interacts with DNA in the cell nucleus. For that, both single- and double-stranded DNA fragments of 50 base pairs in size [35], each labeled with a Cy3 fluorophore, were mixed with either F105 or F145 and separated with 10\% non-denaturing PAGE. No changes in the migration of either SS- or DS-DNA after furanone treatment could be observed, suggesting no interaction (Figure 7). 


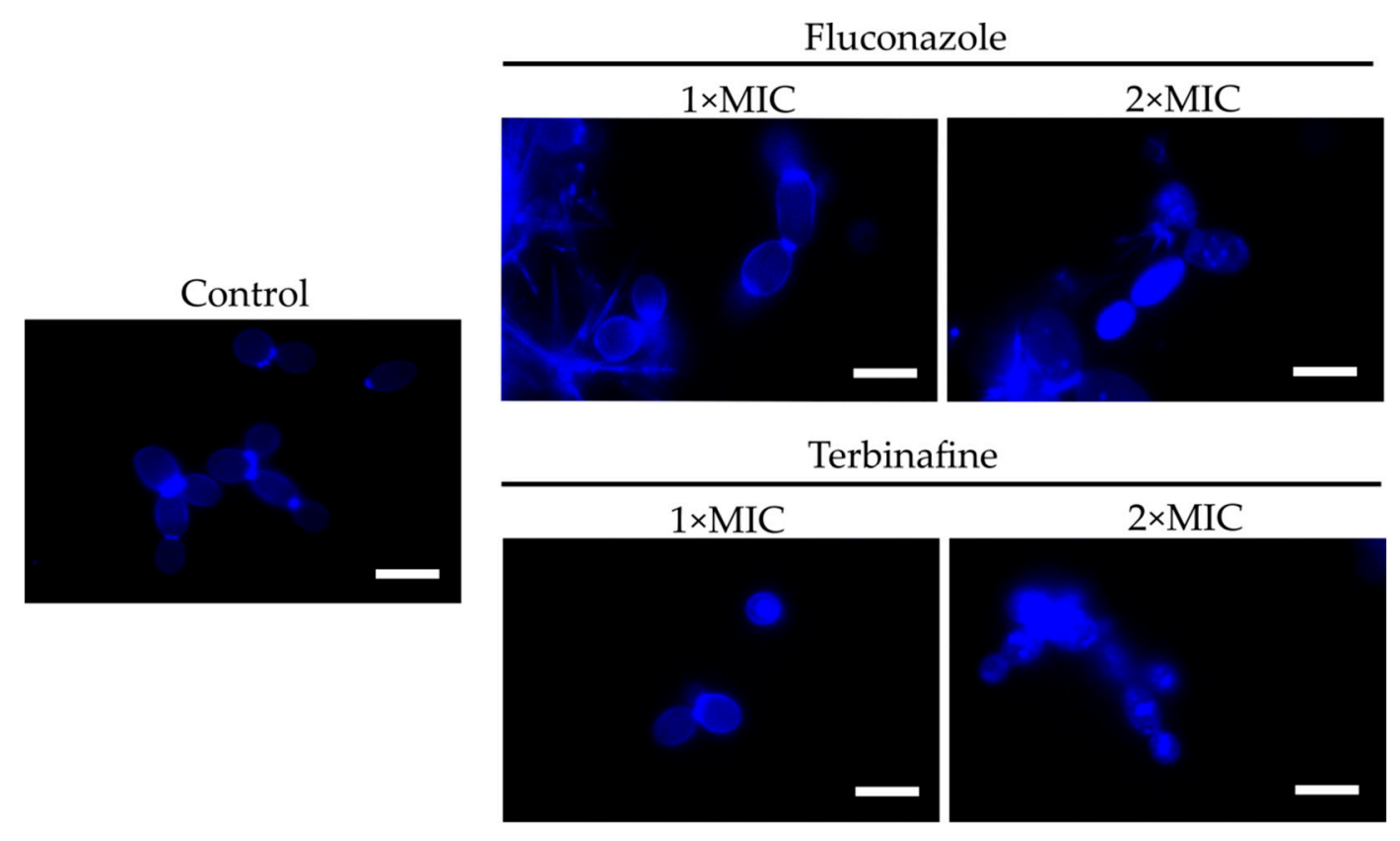

Figure 6. CLSM of C. albicans cells stained for $30 \mathrm{~min}$ with F145 alone (control), or after $4 \mathrm{~h}$ pre-treatment with either fluconazole or terbinafine $(1 \times$ or $2 \times$ MIC) as indicated. Scale bar is $2 \mu \mathrm{m}$.

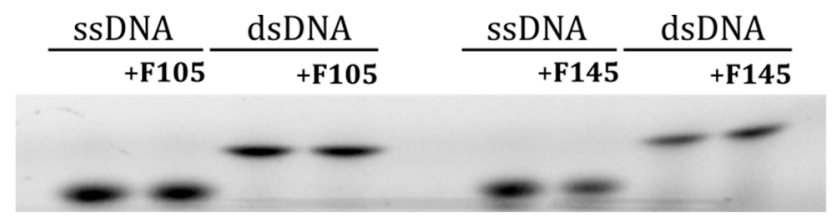

Figure 7. The electrophoretic mobility shift assay (EMSA) of 2(5H)-furanone derivative interactions with single- and double-stranded DNA.

\subsection{Penetration of Fluorescent 2(5H)-Furanone Derivative into C. albicans Biofilm}

Biofilm formation represents one of the major virulence factors contributing to the pathogenesis of $C$. albicans infections. 2(5H)-furanone derivatives F105 and F145 have been previously shown to rapidly penetrate into the biofilm of $S$. aureus $[17,26]$. To investigate the diffusion ability of F145 into the biofilm of $C$. albicans, the fungal cells were grown in RPMI broth for $24 \mathrm{~h}, 48 \mathrm{~h}$, and $72 \mathrm{~h}$, under static conditions to provide mature biofilm formation. F145 was then added into the wells with established biofilm until the final concentration of $50 \mu \mathrm{g} / \mathrm{mL}$ was reached. After $1 \mathrm{~h}$ of incubation, the biofilm was analyzed with CLSM. The fluorescence of F145 was observed throughout all layers of C. albicans biofilms of any age, indicating the penetration of the furanone through the biofilm matrix (Figure 8). Moreover, the fluorescent signal demonstrated a rather homogeneous distribution of F145 through the biofilm with predominant accumulation in the cell walls of individual cells, including those located in the bottom layers. These data suggest that structural analogues of F145 are capable of penetrating through the biofilm matrix of various pathogens. 


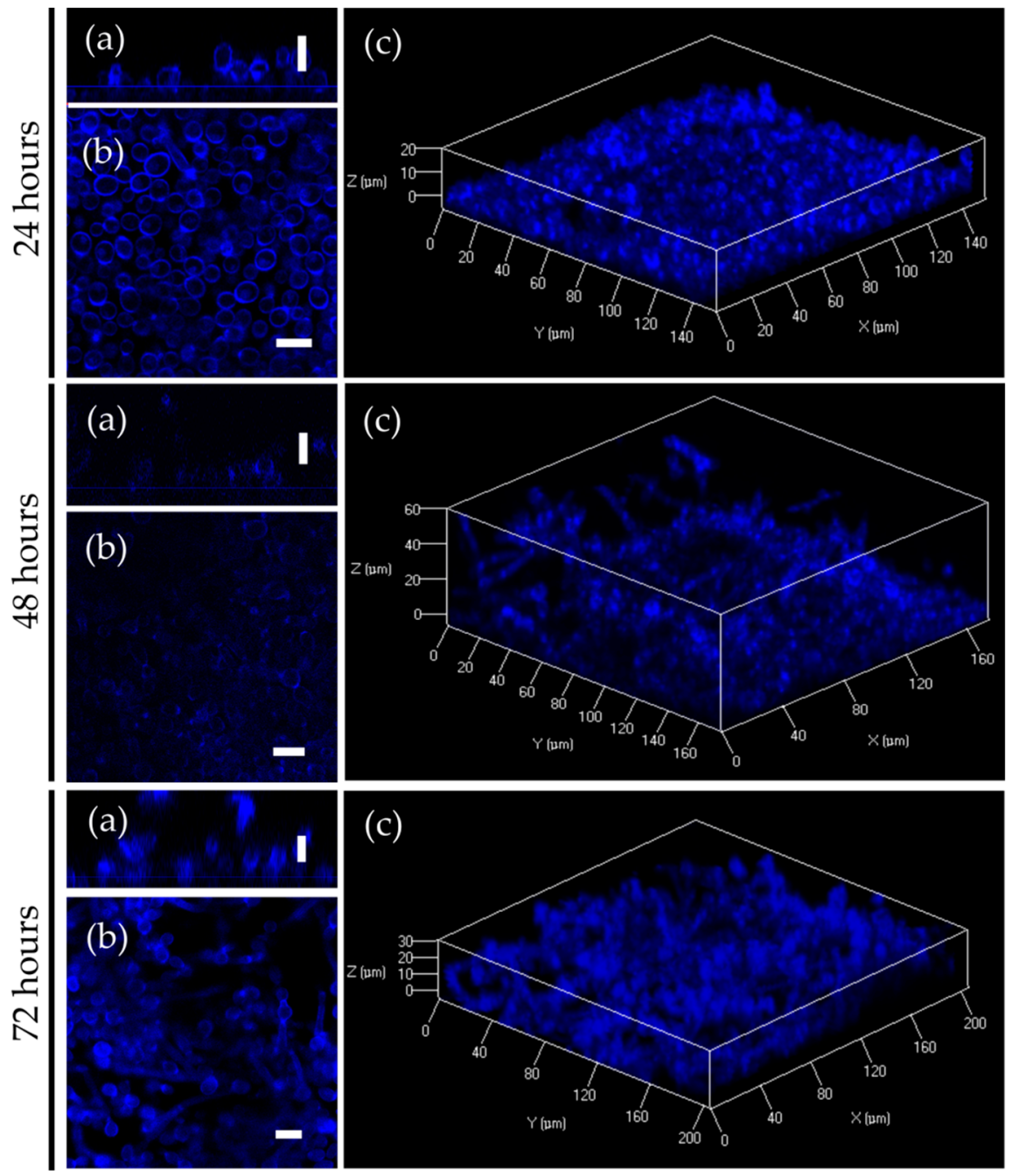

Figure 8. CLSM of C. albicans biofilm treated with F145. (a) X; Y orientation of the biofilm; (b) Z-stack of the biofilm; (c) 3D-model of the biofilm. Scale bar is $10 \mu \mathrm{m}$.

Next, we examined whether F105 was able to potentiate the antifungal activity of fluconazole and terbinafine against mature $24 \mathrm{~h}$ old biofilms of $C$. albicans. Four $C$. albicans clinical isolates $(4940,5012$, 5050, and 5061) were grown for $24 \mathrm{~h}$ to form biofilms. Different concentrations of either fluconazole or terbinafine were then added either alone or in combination with F105 (in concentrations of $16 \mu \mathrm{g} / \mathrm{mL}$ ) to the established C. albicans biofilm. After $24 \mathrm{~h}$ incubation, the CFU count was assessed by drop plate assay [17]. Even F105 alone led to a two-log reduction in the CFU count in the biofilms of $C$. albicans strains 4940, 5012, and 5050 (see Figure 9, points $0 \times$ ). The combination of F105 with either fluconazole or terbinafine provided a further 10-fold decrease of the CFUs, while no complete death of the cells was observed (Figure 9). Taken together, these data suggest that even in combination with F105, fluconazole and terbinafine face the problem of the biofilm barrier, which provides antifungal resistance to $C$. albicans.

However, when F105 and fluconazole were applied in combination, a 3-log reduction in the CFU counts was observed for the strains 4940 and 5012. Moreover, while the biofilm-embedded cells of the strain 5050 were not susceptible to fluconazole at the concentrations tested, in the presence of F105, a 2.5-log decrease of CFU count was achieved. The biofilm-embedded C. albicans 5061 cells were susceptible neither to F105 nor to any of the antifungals even at the highest concentrations tested. Apparently, the biofilm matrix is not permeable for these antifungals, which is required for the facilitation of F105 penetration into the cell. Nevertheless, fast penetration of F145 into the biofilm 
allows its chemotype to be suggested for the development of novel systems to deliver antifungals into the biofilm, for example in the form of multi-pharmacophore drugs, to target biofilm-associated $C$. albicans infections.

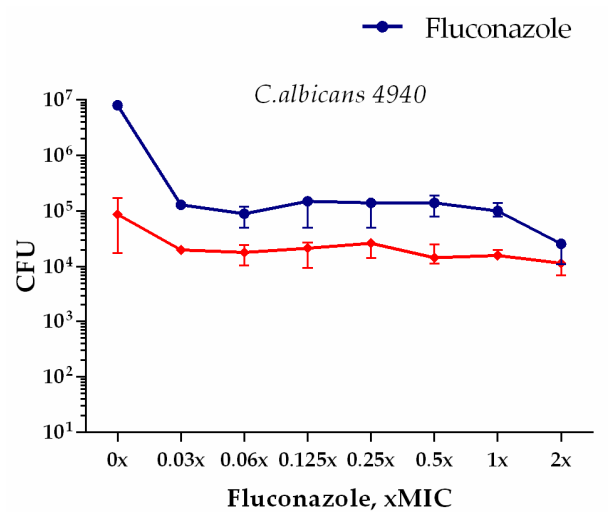

$\rightarrow$ Fluconazole + F-105
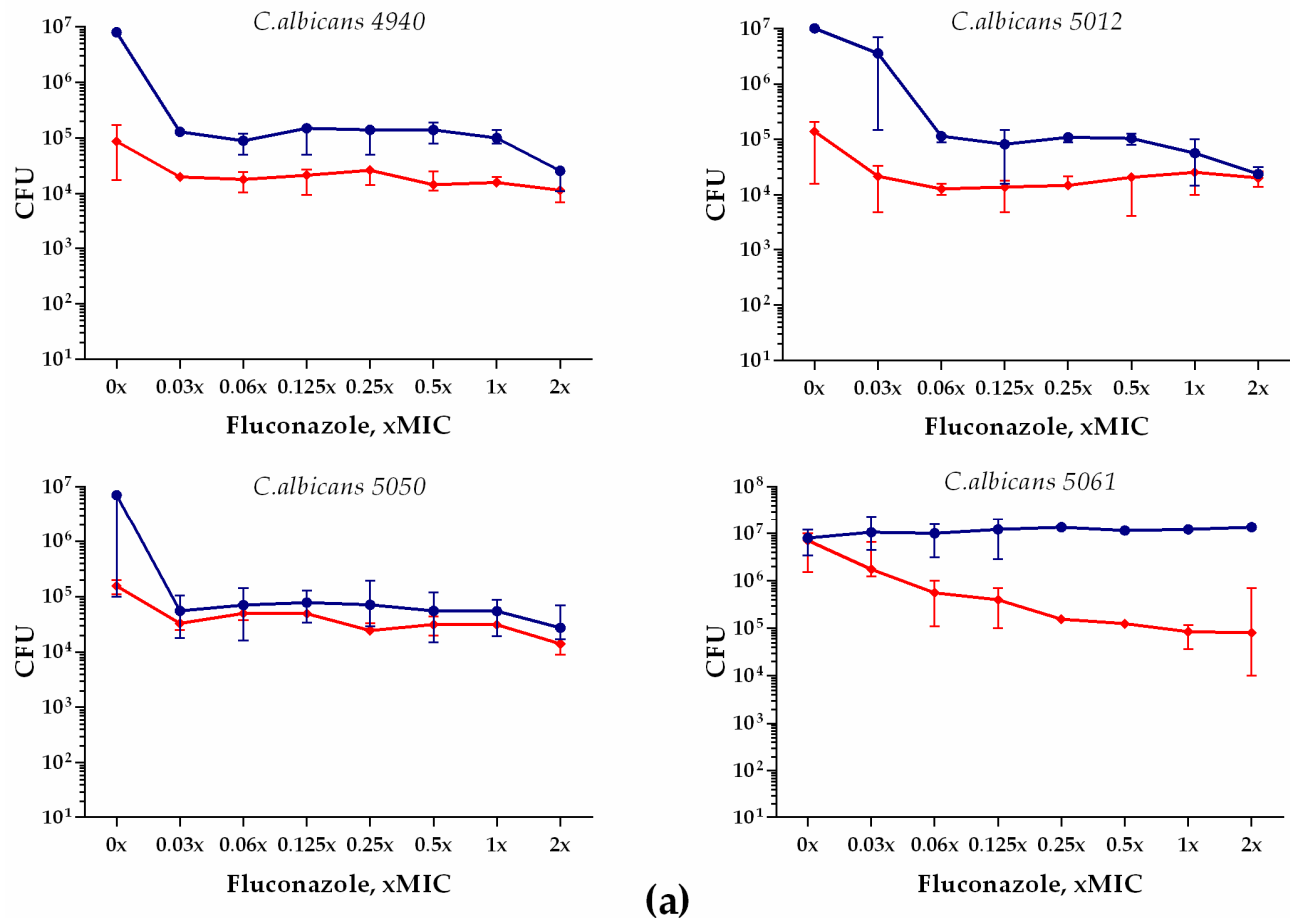

(a)

Terbinafine $\rightarrow$ Terbinafine+F-105
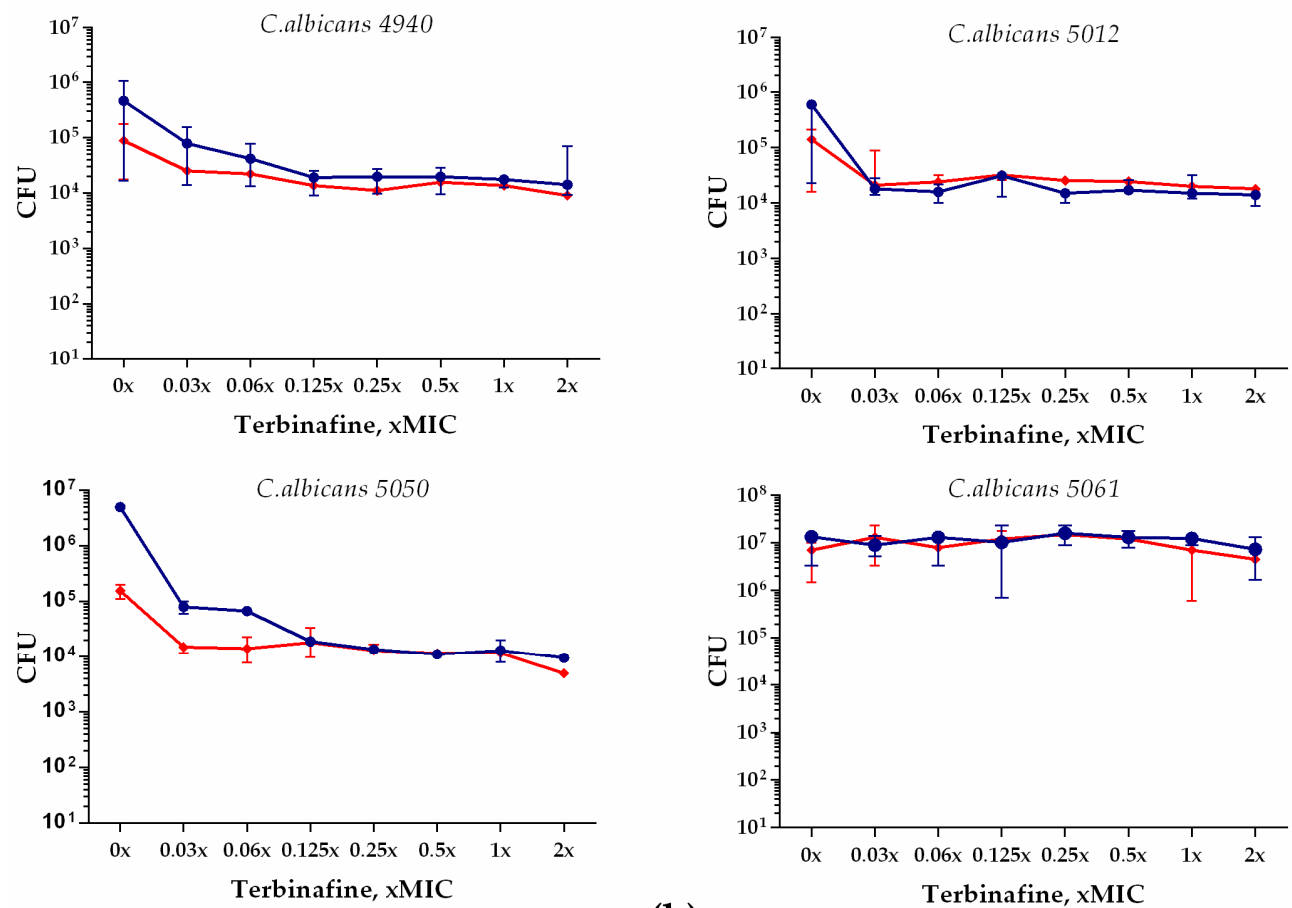

(b)

Figure 9. Antifungal effect of fluconazole (a) or terbinafine (b) alone and in combination with $16 \mu \mathrm{g} / \mathrm{mL}$ F105 against $C$. albicans biofilm. 


\section{Discussion}

The rising frequency of candidiasis caused by C. albicans resistant to antimycotics highlights the spread of drug-resistant strains [10,30] and requires either the development of novel antifungals or the suggestion of alternative approaches to increase the activity of conventional ones. Therefore, the 2(5H)-furanone derivatives exhibiting both biocidal and antibiofilm activity against various bacteria could be of interest $[17,19,24]$. Here, we report an in vitro synergistic effect of the combination of terbinafine and fluconazole with the 2(5H)-furanone derivative F105 for targeting $\mathrm{C}$. albicans clinical isolates. The presence of F105 lowered the MICs of both fluconazole and terbinafine approximately 4-fold (see Tables 2 and 3). Although F105 alone exhibited only moderate antimycotic activity in comparison with these antifungals, in their presence, its own MIC decreased, reaching relevant values of $2-4 \mu \mathrm{g} / \mathrm{mL}$ (see Table 1 ). The synergistic effects of the compounds were also confirmed by measuring the relative membrane potential (Figures 3 and 4). Although the steepness of the DioC ${ }_{2}(3)$ fluorescence drop varied significantly between strains, in general, in the combination of either fluconazole or terbinafine with F105 this decrease was significantly faster, confirming rapid loss of energy supply to the cell. Thus, taking into account the rapid increase of fluconazole- and terbinafine-resistant Candida isolates, the reduction of active concentration of antimycotics could be useful for the treatment of C. albicans strains with intermediate susceptibility to antifungal drugs, and could contribute to the diversity to the currently limited antifungal arsenal.

The mechanism of synergy between F105 and fluconazole or terbinafine seemed to be bilateral. Apparently, both fluconazole and terbinafine could affect the ergosterol composition in the fungal membrane due to the repression of squalene monooxygenase, which in turn can facilitate the penetration of F105 into the cell. This assumption was supported by the fact that FIC of F105 decreased up to 16-fold in the presence of either fluconazole or terbinafine, while the FICs of the latter exhibited a 4 -fold decay only (see Tables 2 and 3). Indeed, the permeability of the C. albicans membrane seemed to be low for the furanones. Thus, the fluorescent furanone derivative F145 penetrated into the cell only after $6 \mathrm{~h}$ of treatment (Figure 5), although in the cells pre-treated with either fluconazole or terbinafine, intracellular fluorescence could be observed after only $30 \mathrm{~min}$ of incubation (Figure 6). These facts allow the speculation that F105 targets intracellular proteins rather than the membrane, as has been shown previously for bacteria [26].

The molecular mechanism of the potentiation of either fluconazole or terbinafine by F105 against $C$. albicans remains unclear. One could hypothesize that F105 facilitates the penetration of small molecules of terbinafine $(\mathrm{M}=291.43 \mathrm{~g} / \mathrm{mol})$ and fluconazole $(\mathrm{M}=306.27 \mathrm{~g} / \mathrm{mol})$ into the cell by modification of the cell wall structure, while no corresponding effect could be observed for the larger molecules of nystatine $(\mathrm{M}=926.09 \mathrm{~g} / \mathrm{mol})$. Another possible mechanism of antifungal activity of F105 could be the disturbance of the biosynthetic apparatus of the cell through direct protein damage, since furanone derivatives can directly interact with a range of proteins both in vitro and in vivo [17,26].

Besides genetically determined resistance, C. albicans forms rigid biofilms which make the cell inaccessible to antifungals. Our results based on the fluorescent $2(5 \mathrm{H})$-furanone derivative (analogue of F105) allowed the conclusion that $2(5 H)$-furanone derivatives rapidly penetrate into C. albicans biofilm (Figure 8), although no complete death of biofilm-embedded yeast could be observed. This could be apparently attributed to the diffusional barrier effect of the biofilm matrix (Figure 9). Nevertheless, since the biofilm formation of C. albicans greatly contributes to its phenotypic drug resistance [13], the chemotypes of F105 and F145 seem to be interesting candidates for inclusion into complex multipharmacophore antifungals for biofilm-associated C. albicans infection treatment. Moreover, the 2(5H)-furanone derivative F105 demonstrated a low risk of resistance development among $B$. cereus and $S$. aureus cells [19]. Considering the widespread occurrence of C. albicans-S. aureus mixed biofilms [36], the 2(5H)-derivative F105 also represents an interesting candidate for targeting complex fungal-bacterial mixed infections. 


\section{Conclusions}

In this work, we showed that 3-chloro-5(S)-[(1R,2S,5R)-2-isopropyl-5- methylcyclohexyloxy]-4[4-methylphenylsulfonyl]-2(5H)-furanone (F105) exhibits pronounced antifungal activity in combination with either fluconazole or terbinafine against resistant $C$. albicans isolates. The relatively high toxicity of F105, with $\mathrm{CC}_{50}$ values in the range of $8-40 \mu \mathrm{g} / \mathrm{mL}$ for different cell lines [17], remains a limitation for its direct translation. Nevertheless, non-toxic concentrations of F105 could increase the efficacy of fluconazole and terbinafine against resistant $C$. albicans strains. This allows the F105 chemotype to be suggested as a promising starting point for the development of complex topical agents for targeting C. albicans infections, while further in vitro and in vivo studies are required.

\section{Materials and Methods}

\subsection{Strains and Growth Conditions}

C. albicans NCTC ${ }^{\circledR 885-653 ~ f r o m ~ t h e ~ N a t i o n a l ~ C o l l e c t i o n ~ o f ~ T y p e ~ C u l t u r e s ~(P e r m, ~ R u s s i a) ~ a n d ~}$ 26 clinical isolates (see Table 1 for the source) from the patients of Kazan Scientific Research Institute of Epidemiology and Microbiology (Kazan, Russia) obtained during 2019 were used for the experiments. Isolates were identified as C. albicans by using AuxaColor 2 Colorimetric sugar-assimilation yeast-identification kit (Bio-Rad) and confirmed via MALDI-TOF mass spectrometry (Bruker Biotyper system, Bruker Daltonics, Germany).

All strains were stored as a $50 \%$ glycerol stock at $-80{ }^{\circ} \mathrm{C}$ and grown in RPMI broth. To obtain a mature biofilm, fungal cells were grown in $35 \mathrm{~mm}$ TC-treated culture plates under static conditions for 24,48 , or $72 \mathrm{~h}$ at $37^{\circ} \mathrm{C}$.

\subsection{Tested Compounds}

3-Chloro-5(S)-[(1R,2S,5R)-2-isopropyl-5-methylcyclohexyloxy]-4-[(4-methylphenyl)sulfonyl]-2(5H)furanone (F105) [17], 3-chloro-5-hydroxy-4-[(4-methylphenylsulfonyl)]-2(5H)-furanone (F70) [25,37], 3-chloro-5(S)-[(1R,2S,5R)-2-isopropyl-5-methylcyclohexyloxy]-4-[4-methylphenylsulfanyl]-2(5H)furanone (F104) [17], the fluorescent 2(5H)-furanone derivative 5-[2-(benzothiazol-2-yl)-4bromophenoxy]-3-chloro-4-[(4-methylphenyl)sulfonyl]-2(5H)-furanone (F145) [26] (see Figure 1 for the structures), and 2-(benzothiazol-2-yl)-4-bromophenol (BTBP) [38] were previously synthesized. The detailed synthesis as well as spectroscopic data can be found in References $[17,25,26,37,38]$. Three antifungal compounds, fluconazole, terbinafine, and nystatin, were used as reference antimycotics. All tested compounds were dissolved in DMSO until final concentrations of $10 \mathrm{mg} / \mathrm{mL}$ were reached for F105, F145, and fluconazole, or $5 \mathrm{mg} / \mathrm{mL}$ for terbinafine and nystatin.

\subsection{Determination of Minimum Inhibitory Concentration (MIC)}

The susceptibility of $C$. albicans to antifungal agents was assessed in accordance with the Clinical Laboratory Standards Institute (CLSI) standardized broth microdilution method. Measures of $100 \mu \mathrm{L}$ of 2-fold serially diluted concentrations of antifungal agents in RPMI broth were mixed with $100 \mu \mathrm{L}$ of C. albicans cell suspensions adjusted to $1-5 \times 10^{5} \mathrm{CFU} / \mathrm{mL}$ in 96 well plates and incubated at $35^{\circ} \mathrm{C}$ for $24 \mathrm{~h}$. The lowest concentration with at least 50\% growth inhibition was determined as the minimum inhibitory concentration. Experiments were performed in biological triplicates with two technical repeats in each, and the medians were calculated.

\subsection{Assessment of Synergy Between F105 and Conventional Antifungal Agents}

To assess a synergy between F105 and antifungal agents, a checkerboard assay was performed as described previously [17]. Briefly, the final concentrations of both compounds ranged from 1/16 to $4 \times \mathrm{MIC}$ for a furanone derivative and from $1 / 256$ to $4 \times \mathrm{MIC}$ for the antifungals. In total, nine dilution steps of antifungals and seven dilution steps of F105 in RPMI broth were obtained. The microwell 
plates were incubated at $35^{\circ} \mathrm{C}$ for $24 \mathrm{~h}$. Each test was performed in triplicate and included a growth control without addition of any antifungal or F105. The fractional inhibitory concentration index (FICI) was counted from the concentrations in the first non-turbid well found in each row and column along the turbidity/non-turbidity interface, and the lowest FICI value was used to characterize the synergy. For the FICI interpretation, we referred to Reference [39]: FICI $<0.5$ corresponds to synergy, $0.5<$ FICI $<4$ corresponds to either additive effects or indifference, while FICI $>4$ corresponds to antagonism.

\subsection{Membrane Potential Evaluation}

Membrane potential was evaluated by detection of 3,3'-diethyloxacarbocyanine iodide $\left(\operatorname{DioC}_{2}(3)\right)$ fluorescence. C. albicans cells were grown for $24 \mathrm{~h}$, harvested, and washed with PBS. Cells were resuspended until a final density of $10^{5} \mathrm{CFU} / \mathrm{mL}$ was reached in PBS supplemented with $\mathrm{DioC}_{2}(3)$ to a final concentration of $10 \mu \mathrm{M}$. After $30 \mathrm{~min}$ preincubation at $25^{\circ} \mathrm{C}, \mathrm{F} 105 \mathrm{and} /$ or antifungals were added and the fluorescence was measured for $60 \mathrm{~min}$ with $10 \mathrm{~min}$ intervals using carboxyfluorescein (FAM) wavelength detection (the excitation and emission wavelengths were 497 and $520 \mathrm{~nm}$, respectively).

\subsection{Confocal Laser Scanning Microscopy}

To assess the localization of F145 within the biofilm and cells, the fungal cells and biofilms were treated with 2(5H)-furanone derivative F145 for $60 \mathrm{~min}$, with subsequent staining with $\mathrm{DioC}_{6}(3)$ and propidium iodide. C. albicans cells and biofilms were analyzed under vital conditions using a direct confocal laser scanning microscope LSM700 (Carl Zeiss AG) at blue (405/410-508 nm), green (488/490-606 nm), and red (543/566-718 nm) channels. The obtained data were visualized using ZEN 12.0 software (Carl Zeiss Microscopy $\mathrm{GmbH}$, Jena, Germany), with further quantification and statistical assessment using in-house developed software [40].

To evaluate whether furanone derivatives could penetrate the fungal cells, the $2(5 \mathrm{H})$-furanone derivative F145 carrying a fluorescent 2-(benzothiazol-2-yl)-4-bromophenoxy moiety was used. 2-(Benzothiazol-2-yl)-4-bromophenol (BTBP) [38] itself was used as a control. Yeasts were grown for $24 \mathrm{~h}$ with agitation in Sabouraud broth, then washed and resuspended in PBS. F145 or BTBP were added until the final concentration of $50 \mu \mathrm{g} / \mathrm{mL}$ and incubation followed for $30 \mathrm{~min}$ or $6 \mathrm{~h}$. Cells were then stained with $\operatorname{DioC}_{6}(3)$ and analyzed with CLSM.

\subsection{Investigation of DNA-Binding Ability of F105}

To assess the DNA-binding ability of F105, two 50 mer self-complementary primers corresponding to $G \ln R$ promoter sequence [35] were melted and annealed. A forward primer was labeled with cyanine3 (Сy3) on 5' end. Measures of $10 \mathrm{nM}$ of DNA were mixed with F105 $(64 \mu \mathrm{g} / \mathrm{mL}$ final concentration) and pre-incubated at $37^{\circ} \mathrm{C}$ in $1 \times \mathrm{TBE}$ buffer in a final reaction volume of $10 \mu \mathrm{L}$. Samples were then separated on an $8 \%$ non-denaturing polyacrylamide gel and visualized on the Bio-RAD ChemiDoc XRS+.

Author Contributions: Conceptualization-I.S.S. and A.R.K. (Airat R. Kayumov); methodology-I.S.S., S.A.L., and A.R.K. (Airat R. Kayumov); investigation-I.S.S., G.D.O., A.E.S., S.A.L., A.M.K.; formal analysis-I.S.S., G.D.O.; resources-V.V.N., A.R.K. (Almira R. Kurbangalieva) and A.R.K. (Airat R. Kayumov); visualization-I.S.S., A.E.S., and M.I.B.; project administration- I.S.S. and A.R.K. (Airat R. Kayumov); supervision-A.R.K. (Airat R. Kayumov); funding acquisition-V.V.N., A.R.K. (Almira R. Kurbangalieva), I.S.S. and A.R.K. (Airat R. Kayumov); writing—original draft preparation-I.S.S.; writing—review and editing S.A.L., V.V.N., A.R.K. (Almira R. Kurbangalieva) M.I.B. and A.R.K. (Airat R. Kayumov). All authors have read and agreed to the published version of the manuscript. 
Funding: The experimental study reported here was funded by RFBR according to the research project No. 20-04-00247 and was performed according to the Russian Government Program of Competitive Development of Kazan Federal University (A.R.K. (Airat R. Kayumov)). I.S. was supported by the Ministry of Science and Higher Education of the Russian Federation and the German Academic Exchange Service (Mikhail Lomonosov Russian-German bilateral travel grant, state assignment \#6.13469.2019/13.2 to Kazan Federal University). The synthetic part of this work was funded by the subsidy allocated to Kazan Federal University for the state assignment in the sphere of scientific activities (4.1493.2017/4.6 to A.R.K. (Almira R. Kurbangalieva)).

Conflicts of Interest: Authors declare no conflict of interest. The funders had no role in the design of the study; in the collection, analyses, or interpretation of data; in the writing of the manuscript, or in the decision to publish the results.

\section{References}

1. Hofs, S.; Mogavero, S.; Hube, B. Interaction of Candida albicans with host cells: Virulence factors, host defense, escape strategies, and the microbiota. J. Microbiol. 2016, 54, 149-169. [CrossRef] [PubMed]

2. Metwalli, K.H.; Khan, S.A.; Krom, B.P.; Jabra-Rizk, M.A. Streptococcus mutans, Candida albicans, and the Human Mouth: A Sticky Situation. Plos Pathog. 2013, 9. [CrossRef] [PubMed]

3. Kashem, S.W.; Kaplan, D.H. Skin Immunity to Candida albicans. Trends Immunol. 2016, 37, 440-450. [CrossRef] [PubMed]

4. Ge, S.H.; Xie, J.; Xu, J.P.; Li, J.; Li, D.M.; Zong, L.L.; Zheng, Y.C.; Bai, F.Y. Prevalence of specific and phylogenetically closely related genotypes in the population of Candida albicans associated with genital candidiasis in China. Fungal Genet. Biol. 2012, 49, 86-93. [CrossRef] [PubMed]

5. Scheibler, E.; Garcia, M.C.R.; da Silva, R.M.; Figueiredo, M.A.; Salum, F.G.; Cherubini, K. Use of nystatin and chlorhexidine in oral medicine: Properties, indications and pitfalls with focus on geriatric patients. Gerodontology 2017, 34, 291-298. [CrossRef] [PubMed]

6. Eschenauer, G.A.; Nguyen, M.H.; Clancy, C.J. Is Fluconazole or an Echinocandin the Agent of Choice for Candidemia. Ann. Pharmacother. 2015, 49, 1068-1074. [CrossRef]

7. Baixench, M.T.; Aoun, N.; Desnos-Ollivier, M.; Garcia-Hermoso, D.; Bretagne, S.; Ramires, S.; Piketty, C.; Dannaoui, E. Acquired resistance to echinocandins in Candida albicans: Case report and review. J. Antimicrob. Chemother. 2007, 59, 1076-1083. [CrossRef]

8. Wiederhold, N.P. Antifungal resistance: Current trends and future strategies to combat. Infect. Drug Resist. 2017, 10, 249-259. [CrossRef]

9. Ryder, N.S.; Wagner, S.; Leitner, I. In vitro activities of terbinafine against cutaneous isolates of Candida albicans and other pathogenic yeasts. Antimicrob. Agents Chemother. 1998, 42, 1057-1061. [CrossRef]

10. Hu, Y.X.; Hu, Y.Q.; Lu, Y.; Huang, S.Y.; Liu, K.X.; Han, X.; Mao, Z.H.; Wu, Z.; Zhou, X.Y. A Case Report of Penile Infection Caused by Fluconazole- and Terbinafine-Resistant Candida albicans. Mycopathologia 2017, 182, 397-402. [CrossRef]

11. Berkow, E.L.; Lockhart, S.R. Fluconazole resistance in Candida species: A current perspective. Infect. Drug Resist. 2017, 10, 237-245. [CrossRef] [PubMed]

12. Corte, L.; Roscini, L.; Colabella, C.; Tascini, C.; Leonildi, A.; Sozio, E.; Menichetti, F.; Merelli, M.; Scarparo, C.; Meyer, W.; et al. Exploring ecological modelling to investigate factors governing the colonization success in nosocomial environment of Candida albicans and other pathogenic yeasts. Sci. Rep. 2016, 6. [CrossRef] [PubMed]

13. Cavalheiro, M.; Teixeira, M.C. Candida Biofilms: Threats, Challenges, and Promising Strategies. Front. Med. 2018, 5. [CrossRef] [PubMed]

14. Wu, H.; Song, Z.; Hentzer, M.; Andersen, J.B.; Molin, S.; Givskov, M.; Hoiby, N. Synthetic furanones inhibit quorum-sensing and enhance bacterial clearance in Pseudomonas aeruginosa lung infection in mice. J. Antimicrob. Chemother. 2004, 53, 1054-1061. [CrossRef]

15. Janssens, J.C.A.; Steenackers, H.; Robijns, S.; Gellens, E.; Levin, J.; Zhao, H.; Hermans, K.; De Coster, D.; Verhoeven, T.L.; Marchal, K.; et al. Brominated Furanones Inhibit Biofilm Formation by Salmonella enterica Serovar Typhimurium. Appl. Environ. Microbiol. 2008, 74, 6639-6648. [CrossRef]

16. Hentzer, M.; Riedel, K.; Rasmussen, T.B.; Heydorn, A.; Andersen, J.B.; Parsek, M.R.; Rice, S.A.; Eberl, L.; Molin, S.; Hoiby, N.; et al. Inhibition of quorum sensing in Pseudomonas aeruginosa biofilm bacteria by a halogenated furanone compound. Microbiol. -Sgm 2002, 148, 87-102. [CrossRef] 
17. Sharafutdinov, I.S.; Trizna, E.Y.; Baidamshina, D.R.; Ryzhikova, M.N.; Sibgatullina, R.R.; Khabibrakhmanova, A.M.; Latypova, L.Z.; Kurbangalieva, A.R.; Rozhina, E.V.; Klinger-Strobel, M.; et al. Antimicrobial Effects of Sulfonyl Derivative of 2(5H)-Furanone against Planktonic and Biofilm Associated Methicillin-Resistant and -Susceptible Staphylococcus aureus. Front. Microbiol. 2017, 8. [CrossRef]

18. Lonn-Stensrud, J.; Landin, M.A.; Benneche, T.; Petersen, F.C.; Scheie, A.A. Furanones, potential agents for preventing Staphylococcus epidermidis biofilm infections? J. Antimicrob. Chemother. 2009, 63, 309-316. [CrossRef]

19. Sharafutdinov, I.S.; Pavlova, A.S.; Khabibrakhmanova, A.M.; Faizova, G.M.; Kurbangalieva, A.R.; Katsunori, T.; Trizna, E.Y.; Baidamshina, D.R.; Bogachev, M.I.; Kayumov, A.R. Targeting Bacillus cereus cells: Increasing efficiency of antimicrobials by the bornyl-possessing 2(5H)-furanone derivative. New Microbiol. 2019.

20. Buchta, V.; Pour, M.; Kubanova, P.; Silva, L.; Votruba, I.; Voprsalova, M.; Schiller, R.; Fakova, H.; Spulak, M. In vitro activities of 3-(halogenated phenyl)-5-acyloxymethyl-2,5-dihydrofuran-2-ones against common and emerging yeasts and molds. Antimicrob. Agents Chemother. 2004, 48, 873-878. [CrossRef]

21. Husain, A.; Alam, M.M.; Shaharyar, M.; Lal, S. Antimicrobial activities of some synthetic butenolides and their pyrrolone derivatives. J. Enzym. Inhib. Med. Chem. 2010, 25, 54-61. [CrossRef] [PubMed]

22. Yang, S.J.; Abdel-Razek, O.A.; Cheng, F.; Bandyopadhyay, D.; Shetye, G.S.; Wang, G.R.; Luk, Y.Y. Bicyclic brominated furanones: A new class of quorum sensing modulators that inhibit bacterial biofilm formation. Bioorganic Med. Chem. 2014, 22, 1313-1317. [CrossRef] [PubMed]

23. Kuehl, R.; Al-Bataineh, S.; Gordon, O.; Luginbuehl, R.; Otto, M.; Textor, M.; Landmann, R. Furanone at Subinhibitory Concentrations Enhances Staphylococcal Biofilm Formation by luxS Repression. Antimicrob. Agents Chemother. 2009, 53, 4159-4166. [CrossRef] [PubMed]

24. Trizna, E.; Latypova, L.; Kurbangalieva, A.; Bogachev, M.I.; Kayumov, A. 2(5H)-Furanone Derivatives as Inhibitors of Staphylococcal Biofilms. BioNanoScience 2016. [CrossRef]

25. Latypova, L.Z.; Saigitbatalova, E.S.; Chulakova, D.R.; Lodochnikova, O.A.; Kurbangalieva, A.R.; Berdnikov, E.A.; Chmutova, G.A. Sulfides, sulfones, and sulfoxides of the furan-2(5H)-one series. synthesis and structure. Russ. J. Org. Chem. 2014, 50, 521-534. [CrossRef]

26. Sharafutdinov, I.S.; Pavlova, A.S.; Akhatova, F.S.; Khabibrakhmanova, A.M.; Rozhina, E.V.; Romanova, Y.J.; Fakhrullin, R.; Lodochnikova, O.A.; Kurbangalieva, A.R.; Bogachev, M.I.; et al. Unraveling the Molecular Mechanism of Selective Antimicrobial Activity of 2(5H)-Furanone Derivative against Staphylococcus aureus. Int. J. Mol. Sci. 2019, 20, 694. [CrossRef] [PubMed]

27. Sergeyev, Y.V.; Shpigel, B.I.; Sergeev, A.Y. Pharmacotherapy of Mycosis; Medicine for Everyone: Moscow, Russia, 2003; p. 200.

28. Trizna, E.Y.; Khakimullina, E.N.; Latypova, L.Z.; Kurbangalieva, A.R.; Sharafutdinov, I.S.; Evtyugin, V.G.; Babynin, E.V.; Bogachev, M.I.; Kayumov, A.R. Thio Derivatives of 2(5H)-Furanone As Inhibitors against Bacillus subtilis Biofilms. Acta Nat. 2015, 7, 102-107. [CrossRef]

29. Fjaervik, E.; Zotchev, S.B. Biosynthesis of the polyene macrolide antibiotic nystatin in Streptomyces noursei. Appl. Microbiol. Biotechnol. 2005, 67, 436-443. [CrossRef]

30. Whaley, S.G.; Berkow, E.L.; Rybak, J.M.; Nishimoto, A.T.; Barker, K.S.; Rogers, P.D. Azole Antifungal Resistance in Candida albicans and Emerging Non-albicans Candida Species. Front. Microbiol. $2017,7$. [CrossRef]

31. Klis, F.M.; Sosinska, G.J.; de Groot, P.W.J.; Brul, S. Covalently linked cell wall proteins of Candida albicans and their role in fitness and virulence. Fems Yeast Res. 2009, 9, 1013-1028. [CrossRef]

32. Chaffin, W.L. Candida albicans cell wall proteins. Microbiol. Mol. Biol. Rev. 2008, 72, 495. [CrossRef]

33. Ene, I.V.; Heilmann, C.J.; Sorgo, A.G.; Walker, L.A.; de Koster, C.G.; Munro, C.A.; Klis, F.M.; Brown, A.J.P. Carbon source-induced reprogramming of the cell wall proteome and secretome modulates the adherence and drug resistance of the fungal pathogen Candida albicans. Proteomics 2012, 12, 3164-3179. [CrossRef]

34. Angiolella, L.; Micocci, M.M.; D’Alessio, S.; Girolamo, A.; Maras, B.; Cassone, A. Identification of major glucan-associated cell wall proteins of Candida albicans and their role in fluconazole resistance. Antimicrob. Agents Chemother. 2002, 46, 1688-1694. [CrossRef]

35. Fedorova, K.; Kayumov, A.; Woyda, K.; Ilinskaja, O.; Forchhammer, K. Transcription factor TnrA inhibits the biosynthetic activity of glutamine synthetase in Bacillus subtilis. Febs Lett. 2013, 587, 1293-1298. [CrossRef] 
36. Kean, R.; Rajendran, R.; Haggarty, J.; Townsend, E.M.; Short, B.; Burgess, K.E.; Lang, S.; Millington, O.; Mackay, W.G.; Williams, C.; et al. Candida albicans Mycofilms Support Staphylococcus aureus Colonization and Enhances Miconazole Resistance in Dual-Species Interactions. Front. Microbiol. 2017, 8, 1-11. [CrossRef] [PubMed]

37. Kayumov, A.R.; Khakimullina, E.N.; Sharafutdinov, I.S.; Trizna, E.Y.; Latypova, L.Z.; Hoang Thi, L.; Margulis, A.B.; Bogachev, M.I.; Kurbangalieva, A.R. Inhibition of biofilm formation in Bacillus subtilis by new halogenated furanones. J. Antibiot. 2015, 68, 297-301. [CrossRef]

38. Otsubo, T.; Minami, A.; Fujii, H.; Taguchi, R.; Takahashi, T.; Suzuki, T.; Teraoka, F.; Ikeda, K. 2-(Benzothiazol-2-yl)-phenyl-beta-D-galactopyranoside derivatives as fluorescent pigment dyeing substrates and their application for the assay of beta-D-galactosidase activities. Bioorganic Med. Chem. Lett. 2013, 23, 2245-2249. [CrossRef] [PubMed]

39. Odds, F.C. Synergy, antagonism, and what the chequerboard puts between them. J. Antimicrob. Chemother. 2003, 52, 1. [CrossRef] [PubMed]

40. Bogachev, M.I.; Volkov, V.Y.; Markelov, O.A.; Trizna, E.Y.; Baydamshina, D.R.; Melnikov, V.; Murtazina, R.R.; Zelenikhin, P.V.; Sharafutdinov, I.S.; Kayumov, A.R. Fast and simple tool for the quantification of biofilm-embedded cells sub-populations from fluorescent microscopic images. PLoS ONE 2018, 13. [CrossRef]

(C) 2020 by the authors. Licensee MDPI, Basel, Switzerland. This article is an open access article distributed under the terms and conditions of the Creative Commons Attribution (CC BY) license (http://creativecommons.org/licenses/by/4.0/). 